Abstract: $250 / 250$

Introduction: $548 / 1500$

Article: $3477 / 3500$

Tables: 2

Figures: 3

References: 57

\title{
Polygenic risk for psychiatric disorder reveals distinct association profiles across social behaviour in the general population
}

Running title: Polygenic psychiatric risk and social behaviour

Fenja Schlag ${ }^{1}$, Andrea Allegrini ${ }^{2,3}$, Jan Buitelaar ${ }^{4,5,6}$, Ellen Verhoef ${ }^{1}$, Marjolein van

Donkelaar $^{1}$, Robert Plomin ${ }^{2}$, Kaili Rimfeld ${ }^{2}$, Simon Edward Fisher ${ }^{1,4}$, Beate St Pourcain ${ }^{1,4,7,8}$

1. Language and Genetics, MPI for Psycholinguistics, Wundtlaan 1, 6525 XD Nijmegen, The Netherlands

2. Social, Genetic and Developmental Psychiatry Centre, Institute of Psychiatry, Psychology \& Neuroscience, King's College London, Memory Ln, Camberwell, London SE5 8AF, London, UK

3. Psychology and Language Sciences, University College London, 26 Bedford Way, Bloomsbury, London WC1H OAP, London, UK

4. Donders Institute for Brain, Cognition and Behaviour, Radboud University, Kapittelweg 29 6525 EN Nijmegen, The Netherlands

5. Karakter Child and Adolescent Psychiatry University Centre, Reinier Postlaan 12, 6525 GC Nijmegen, The Netherlands

6. Department of Cognitive Neuroscience, Radboud University Medical Center, Geert Grooteplein 21, 6525 EZ Nijmegen, The Netherlands

7. MRC Integrative Epidemiology Unit, University of Bristol, Oakfield House, Oakfield Grove, Bristol, BS8 2BN, UK

8. Population Health Sciences, University of Bristol, 5 Tyndall Avenue, Bristol, BS8 1UD, UK

Corresponding authors: Fenja Schlag and Beate St Pourcain

Postal address: Max Planck Institute for Psycholinguistics, Wundtlaan 1, 6525 XD Nijmegen, the Netherlands 
e-mail Fenja Schlag: fenja.schlag@mpi.nl / Phone: +31 243521946

e-mail Beate St Pourcain: beate.stpourcain@mpi.nl / Phone: +3124 3521964 / Fax: +31 24

3521213

e-mail Andrea Allegrini: andrea.allegrini@kcl.ac.uk; e-mail Jan Buitelaar:

jan.buitelaar@radboudumc.nl; e-mail Ellen Verhoef: ellen.verhoef@mpi.nl; email Marjolein van Donkelaar: marjolein.vandonkelaar@mpi.nl; e-mail Robert Plomin:

robert.plomin@kcl.ac.uk; e-mail Kaili Rimfeld: kaili.rimfeld@kcl.ac.uk; e-mail Simon Fisher:

simon.fisher@mpi.nl

Requests for reprints should be sent to the corresponding authors. 


\section{Abstract}

Many complex psychiatric disorders are characterised by a spectrum of social difficulties. These symptoms lie on a behavioural dimension that is shared with social behaviour in the general population, with substantial contributions of genetic factors. However, shared genetic links may vary across psychiatric disorders and social symptoms. Here, we systematically investigate heterogeneity in shared genetic liabilities with attentiondeficit/hyperactivity disorder (ADHD), autism spectrum disorders (ASD), bipolar disorder (BP), major depression (MD) and schizophrenia, across a spectrum of different social symptoms. Specifically, longitudinally assessed low-prosociality and peer-problem scores in two UK population-based/community-based cohorts (ALSPAC, $\mathrm{N} \leq 6174,4-17$ years; TEDS, $\mathrm{N} \leq 7112$, 4-16 years; parent- and teacher-reports) were regressed on polygenic risk scores for ADHD, ASD, BP, MD, and schizophrenia, as informed by genome-wide summary statistics from large consortia, using negative binomial regression models. Across ALSPAC and TEDS, we replicated univariate polygenic associations between social behaviour and risk for ADHD, MD, and schizophrenia. Modelling univariate genetic effects across both cohorts with random-effect meta-regression revealed evidence for polygenic links between social behaviour and ADHD, ASD, MD, and schizophrenia risk, but not BP, where differences in age, reporter and social trait captured $45-88 \%$ in univariate effect variation. For ADHD, MD, and ASD polygenic risk, we identified stronger association with peer problems than low prosociality, while schizophrenia polygenic risk was solely associated with low prosociality. The identified association profiles suggest marked differences in the social genetic architecture underlying different psychiatric disorders when investigating populationbased social symptoms across 13 years of child and adolescent development. 


\section{Introduction}

Many heritable psychiatric disorders such as attention-deficit/hyperactivity disorder (ADHD), autism spectrum disorders (ASD), bipolar disorder (BP), major depression (MD) or schizophrenia are characterised by social-behavioural difficulties. In ADHD, these predominantly include peer problems ${ }^{1}$, while ASD is characterised by deficits in social interaction and communication ${ }^{2}$. Individuals with BP can suffer from social withdrawal and poor social functioning ${ }^{3}$, and, similarly, those with MD may show social withdrawal and disrupted social processing ${ }^{4}$. Individuals with schizophrenia often have poor social cognition and lack social interest ${ }^{5}$.

The underlying social-behavioural difficulties can be diverse. They may reflect a lack of positive interactions involving low prosocial behaviour reflected in limited helping, sharing and cooperating with others ${ }^{6}$. Alternatively, peer problems describe problematic interactions such as social withdrawal, being bullied, and the inability to get along with others ${ }^{7}$. Moreover, social symptoms change throughout development and across different social environments ${ }^{8}$. Therefore, social-behavioural difficulties may reflect different problems depending on developmental stage, social environment as reported by teachers or parents, and different types of skill sets. The aetiology of social problems in psychiatric disorders has, however, been little characterised.

Social behaviour is known to be heritable. Twin studies have reported heritability estimates of 0.38 to $0.76^{9-11}$ for prosocial behaviour and 0.41 to $0.83^{9,12}$ for peer problems, with variation across developmental stages ${ }^{11,12}$, reporters ${ }^{9,10}$ and social traits ${ }^{9}$ in communitybased samples. Heritability estimates as captured by single-nucleotide polymorphisms (SNPs; SNP- $\mathrm{h}^{2}$ ) range between 0.02 to 0.27 for parent-rated peer problems in the general population, with larger estimates during adolescence compared to childhood ${ }^{12}$ suggesting developmental changes in genetic architectures.

One of the grand challenges in psychiatric genetics is to understand how common genetic risk, can manifest as a spectrum of diverse symptoms. Large genome-wide efforts in psychiatric genetics have demonstrated the SNP- $h^{2}$ of ADHD $(0.22)^{13}$, ASD $(0.11)^{14}$, BP $(0.18)^{15}, M D(0.09)^{16}$ and schizophrenia (0.22; Supplementary Table 1$)^{17}$. Social-behavioural difficulties in psychiatric disorder can be understood as the extreme end of a behavioural dimension that is shared with social traits in the general population ${ }^{18}$. These may be captured by polygenic links that differ developmentally, by different reporters and across different social symptoms, potentially reflecting distinct psychopathologies. A systematic comparison of social-behavioural difficulties, especially across neurodevelopmental disorders has, however, not yet been carried out. 
In this open science framework registered study ${ }^{19}$, we systematically investigate genetic links between psychiatric disorders and child and adolescent social behaviour in the general population, studying the heterogeneity in polygenic associations across different ages, reporters and social traits, via a two-stage approach:

Within stage 1, we assess the relationship between polygenic risk scores for ADHD, ASD, BP, MD, and schizophrenia risk, as studied by large clinical consortia, and socialbehavioural scores for low prosociality and peer problems between the ages of 7 and 17 years, as reported by parents or teachers in the population-based UK Avon Longitudinal Study for Parents and Children (ALSPAC) ${ }^{20}$, and follow up findings with matching scores (416 years; parent- and teacher-reports) in the UK community-based Twins Early Development Study (TEDS) ${ }^{21}$.

Within stage 2, we model differences in polygenic associations as predicted by age-, reporter-, and trait-specific social-behavioural symptoms using a random-effects metaregression approach, combining univariate findings from ALSPAC and TEDS, and identify and compare social-behavioural association patterns for each disorder.

\section{Samples and methods}

\section{Genome-wide summary statistics for psychiatric disorder}

We studied genome-wide summary statistics for five psychiatric disorders as published by the Psychiatric Genomic Consortium (PGC), the Danish Lundbeck Foundation Initiative for Integrative Psychiatric Research (iPSYCH) and/or the UK Biobank (UKBB): ADHD-PGC/iPSYCH ${ }^{13}$, ASD-PGC/iPSYCH ${ }^{14}$, BP-PGC ${ }^{15}, \quad$ MD-PGC/UKBB ${ }^{16}$, and schizophrenia-PGC ${ }^{17}$. Cohort details including ancestry, size, imputation reference panel, symptoms and age-of-onset of the disorder are described in the Supplement (Supplementary Information, Supplementary Table 1).

\section{Social behaviour in the general population}

ALSPAC is a UK population-based longitudinal pregnancy-ascertained birth cohort with birth dates between 1991 and $1992^{20,22}$. Ethical approval for the study was obtained from the ALSPAC Ethics and Law Committee and the Local Research Ethics Committees. Consent for biological samples has been collected in accordance with the Human Tissue Act (2004). Informed consent for the use of data collected via questionnaires and clinics was obtained from participants following the recommendations of the ALSPAC Ethics and Law Committee at the time (Supplementary Information). 
TEDS is a community-based longitudinal study of $>10,000$ twin pairs representative of England and Wales, recruited from 1994 to 1996 births $^{21}$. Ethical approval for the study was granted by King's College London's ethics committee for the Institute of Psychiatry, Psychology and Neuroscience (05.Q0706/228), and written informed consent was given by the parents prior to data collection.

Phenotype information: Prosocial behaviour and peer problems were assessed in ALSPAC and TEDS children (Supplementary Information, Table 1) using standardised behavioural screening questionnaires. Both, prosocial behaviour (here recoded as lowprosociality scores) and peer problems were assessed using subscales of the Strengthsand-Difficulties questionnaire $\left(\mathrm{SDQ}^{23}\right)$, based on parent- and teacher-reports at the same ages. In ALSPAC, parent-reported (predominantly mother-reported) behaviour was measured at the ages of $7,10,12,13$ and 17 years and in TEDS at the ages of 4, 7, 9, 11, 14 , and 16 (prosocial scores only) years. In addition, teacher reports were obtained at the ages of 8 and 11 years in ALSPAC and at the ages of 9, 12, and 14 years in TEDS. Both scores are phenotypically modestly to moderately correlated with each other (Supplementary Tables 2,3).

Table 1 here

\section{Univariate polygenic scoring analyses in ALSPAC and TEDS}

Polygenic scoring analyses: Consistent with current guidelines ${ }^{24}$, we constructed polygenic risk scores (PRS) for each disorder (ADHD, ASD, BP, MD and schizophrenia) within ALSPAC and TED using a clumping and thresholding approach (risk-variant selection thresholds $0.001 \leq P_{\mathrm{T}}<1$ ), based on high-quality genome-wide imputed SNPs (Supplementary Information).

Within ALSPAC, we studied unrelated children and adolescents (genomic relatedness $<0.125$ ). We regressed untransformed social-behavioural scores (peer problem or low prosociality) on Z-standardised PRS using a negative binomial model, adjusting for covariate effects of sex, age, and the first two PCs (R:MASS; Supplementary Information). Within TEDS, we analysed pairs of dizygotic twins and a single twin of each monozygotic pair. PRS association analyses were carried out using a multi-level negative binomial regression approach (R:Ime4, v.1.1-26 ${ }^{25}$ ), with a random intercept to adjust for family relatedness, and fixed effects for PRS adjusting for covariate effects of sex, age, the first ten PCs, genotyping-batch, and genotyping-chip effects. For both models the negative binomial 
and multi-level negative binomial model, beta coefficients indicate the change in log counts of social score by one SD change in PRS (PRS effects). We tested the predictive ability of PRS using $\Delta$ McFadden's- $R^{2}$ (Supplementary Information) ${ }^{26}$.

Multiple-testing correction: Using Matrix Spectral Decomposition (matSpD) ${ }^{27}$, we accounted for 14 interrelated social-behavioural scores (Supplementary Table 2) and five psychiatric disorders in ALSPAC by identifying an effective number of 10 independent variables, and adjusting the multiple-testing burden of all univariate PRS analyses to $0.05 /(10 * 5)=0.001$. For follow-up analyses in TEDS, with an effective number of 12 independent variables, the multiple-testing burden under a one-sided test was adjusted to $0.1 /\left(12^{*} 5\right)=0.0017$, accounting for 15 interrelated scores and five psychiatric disorders (Supplementary Table 3).

Power analyses: We estimated the power to detect PRS effects in the discovery cohort (ALSPAC) using the R software package avengeme ${ }^{28}$ (Supplementary Information), assessing the influence of trait- or disorder-specific SNP- ${ }^{2}$ and trait-disorder covariance.

\section{Meta-regression of polygenic effects}

Meta-regression models: For each disorder, we combined univariate PRS estimates for SDQ subscales across ALSPAC and TEDS using a random-effect meta-regression model (R:metafor, v.2.1-0 $0^{29}$, Supplementary Information). In brief, we systematically assessed whether heterogeneity in PRS association effects (based for simplicity on a representative PRS risk variant selection threshold of $P_{\mathrm{T}} \leq 0.1$ ) can be attributed to differences in social behaviour explained by the median age of assessment, reporter (parent vs teacher), and SDQ-based social trait (low prosociality versus peer problems). For each disorder, we fitted a full model including a random intercept accounting for repeated measures (nested within cohort) as well as fixed effects for age-, reporter-, trait- and cohortspecific effects. The most parsimonious model was identified by dropping successively fixed effects from the model (likelihood-ratio test at $P>0.05$ ) and assessing residual heterogeneity (Cochran's $Q$ test, Supplementary Information). The inter-relatedness of PRS association effects across SDQ-based social scores within each cohort was accounted for by constructing a composite variance covariance matrix analogous to models accounting for correlated phylogenetic histories ${ }^{30}$.

Multiple-testing correction: A threshold of $P \leq 0.01$ (0.05/five disorders) was applied.

\section{Results}


medRxiv preprint doi: https://doi.org/10.1101/2021.06.28.21259532; this version posted July 1, 2021. The copyright holder for this preprint (which was not certified by peer review) is the author/funder, who has granted medRxiv a license to display the preprint in perpetuity. It is made available under a CC-BY-NC-ND 4.0 International license .

\section{Stage 1: Univariate association analyses}

Discovery analyses in ALSPAC: We assessed the univariate association between each of the 14 population-based social-behavioural scores in ALSPAC, including lowprosociality and peer problem scores between the ages of 7 and 17 years, as reported by parents or teachers, and five disorder-specific PRS (Supplementary Table 1, ADHD, ASD, $\mathrm{BP}, \mathrm{MD}$, and schizophrenia; 70 analyses; multiple-testing threshold of $P \leq 0.001$ ). All social scores were skewed, with most children showing little difficulties in prosocial behaviour and peer interactions (Table 1). Consequently, we assessed genetic associations with a negative binomial regression model, given the better fit of a count data model compared to a linear model (Supplementary Table 4). PRS effects were fitted across multiple risk variant selection thresholds $\left(0.001 \leq P_{\mathrm{T}}<1\right.$, Supplementary Tables 5,6, Figure 1), but are here, for simplicity, reported at $P_{\mathrm{T}} \leq 0.1$.

Many social-behavioural scores were associated with polygenic risk for ADHD, MD and schizophrenia. For ADHD-PRS, the strongest association was identified for teacherreported peer problems at the age of 11 years $\left(\beta_{\text {ADHD_11Y }_{1}}(S E)=0.10(0.025), \Delta\right.$ McFadden's$\mathrm{R}^{2}=0.0013, P=2.5 \times 10^{-5}$; Figure1a,b). MD-PRS was most strongly associated with parentreported peer problems scores at the age of 13 years $\left(\beta_{M D_{-} 13 Y}(S E)=0.12(0.019)\right.$, $\Delta$ McFadden's- $R^{2}=0.0026, P=2.6 \times 10^{-10}$; Figure1g,h). Associations between schizophreniaPRS and social traits were strongest for teacher-rated low-prosociality scores at 11 years $\left(\beta_{S C Z}{ }_{11 Y}(S E)=0.07(0.019), \Delta\right.$ McFadden's- $R^{2}=8.0 \times 10^{-4}, P=2.2 \times 10^{-4}$; Figure1i,j). For ASDPRS, no univariate association with social symptoms at $P_{\mathrm{T}} \leq 0.1$ passed the multiple-testing threshold. However, at less stringent $P_{\mathrm{T}}$ thresholds, association with parent-reported low prosociality at the age of 7 years was present (for example at $P_{\mathrm{T}}<0.5$,

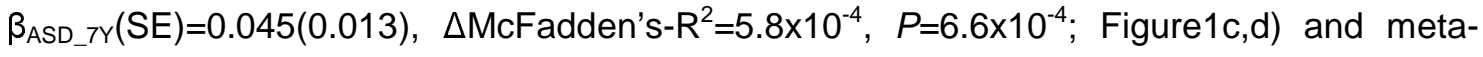
analysing univariate ASD-PRS effects across $P_{\mathrm{T}} \leq 0.1$ yielded further support for association (data not shown). There was little evidence for association between BP-PRS and any of the studied social measures (Figure1e,f).

Power analyses showed that across all studied psychiatric conditions, our study had sufficient power under the assumption of fixed trait-disorder covariance (equivalent to the SNP- $\mathrm{h}^{2}$ of the disorder; Supplementary Table 7; Supplementary Information; Supplementary Figures 1,2; dotted lines). Once data-driven covariance patterns and, thus, trait architectures were considered, power curves followed observed associations (Supplementary Figures 1,2; solid lines), largely, independent of trait SNP- $\mathrm{h}^{2}$ (Supplementary Table 8). Only for polygenic BP and polygenic ASD risk (except for social scores at age 7 years) the power was $<80 \%$ (at $\left.P_{\mathrm{T}}<0.1\right)$, irrespective of the studied social symptoms, consistent with the lack in univariate associations. 
Follow-up analyses in TEDS: Subsequently, we studied the univariate association of polygenic risk for ADHD, ASD, BP, MD, and schizophrenia (at $0.001 \leq P_{\mathrm{T}}<1$ ) with 15 ALSPAC-matching community-based social-behavioural scores in TEDS. Parent- and teacher-reported low-prosociality and peer-problem scores were longitudinally assessed between 4 and 16 years, showing skewed distributions (Table 1, Supplementary Table 9). At $P_{\mathrm{T}} \leq 0.1$, we replicated evidence for association between social-behavioural scores and polygenic risk for ADHD, MD and schizophrenia (75 analyses; Figure 2, Supplementary Tables 10,11; multiple-testing threshold of $P \leq 0.0017)$. In addition, we observed evidence for association between ASD-PRS and peer problems that was strongest in parent-reported scores at the age of 11 years $\left(\beta_{A S D \_11 Y}(S E)=0.093(0.018), \Delta\right.$ McFadden's- $R^{2}=0.0015$, $P=2.7 \times 10^{-7}$; Figure $\left.2 \mathrm{~g}, \mathrm{~h}\right)$. As observed in ALSPAC, we did not find association between BPPRS and any of the studied social measures in TEDS (Figure2e,f).

Figure1,2 here

\section{Stage 2: Meta-regression of polygenic association signals in ALSPAC and TEDS}

For each disorder, we combined univariate polygenic PRS estimates for the 29 SDQbased social scores from both ALSPAC and TEDS, using a random-effects meta-regression approach (5 analyses, multiple-testing threshold $P \leq 0.01$ ). Specifically, we modelled heterogeneity in PRS effect estimates as predicted by age-, reporter-, and trait-specific differences in social behaviour, captured by the fixed-effect meta-regression estimates $\theta$. For each disorder, we first fitted a full meta-regression model and, subsequently, dropped predictors to identify the most parsimonious model based on likelihood-ratio tests (Supplementary Tables 12,13, Supplementary Figures 3-7).

Meta-regression analyses provided evidence for association between social behaviour and PRS for ADHD, ASD, MD, and schizophrenia, but not BP. Across disorders, polygenic effects varied with age, reporter, and, especially, social trait (Table 2). As there was little evidence for cohort-specific fixed effects, these effects were omitted from the most parsimonious models throughout. For ADHD-PRS, the most parsimonious meta-regression model provided evidence for an increase in PRS effects with age $\left(\theta_{\text {age }(Y)}(\mathrm{SE})=0.0025\left(8.9 \times 10^{-}\right.\right.$ $\left.\left.{ }^{4}\right), \quad P=0.0042\right)$, teacher-reported scores $\left(\theta_{\text {teacher_report }}(\mathrm{SE})=0.044(0.0085), \quad P=2.5 \times 10^{-7}\right)$ and peer problems $\left(\theta_{\text {peer_problems }}(\mathrm{SE})=0.03(0.0089), P=7.3 \times 10^{-4}\right)$. Likewise, the meta-regression model for MD-PRS showed an increase in PRS effect with age $\left(\theta_{\text {age }(Y)}(S E)=0.0035\left(9.5 \times 10^{-}\right.\right.$ $\left.\left.{ }^{4}\right), P=1.9 \times 10^{-4}\right)$ and peer problems $\left(\theta_{\text {peer_problems }}(S E)=0.048(0.0093), P=2.8 \times 10^{-7}\right)$. In contrast 
to $A D H D$ and $M D$, the most parsimonious model for schizophrenia revealed a decrease in PRS effects for peer problems $\left(\theta_{\text {peer_problems }}(S E)=-0.027(0.0094), P=0.0033\right)$. As there was a trend for a small positive age-effect that captured a considerable proportion of effect heterogeneity, this effect was retained in the model. For ASD-PRS, we observed an increase in PRS effect for peer problems $\left(\theta_{\text {peer_problems }}(\mathrm{SE})=0.037(0.0083), P=7.9 \times 10^{-6}\right)$ consistent with meta-analytic but not univariate analyses in ALSPAC. The most parsimonious model based on BP-PRS revealed little evidence for association with any social symptoms.

Predicted heterogeneity in PRS effects for ADHD, ASD, MD and (Figure 3; Supplementary Figures 3-7) can be summarised as follows: Meta-analytically predicted PRS effects $(\hat{\beta})$ indicate an association of ADHD-PRS with low prosociality based on teacher-

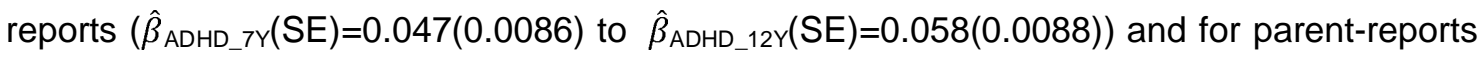
only from the age of 11 years onwards $\left(\hat{\beta}_{\mathrm{ADHD} \_} 11 \mathrm{Y}(\mathrm{SE})=0.013(0.0066)\right.$ to $\hat{\beta}_{\text {ADHD_17Y }}(\mathrm{SE})=0.028(0.0093)$ ); ADHD-PRS are also associated with peer problems based on both parent-reports $\left(\hat{\beta}_{\text {ADHD_4Y }}(\mathrm{SE})=0.025(0.0094)\right.$ to $\left.\hat{\beta}_{\text {ADHD_17Y }_{1}(S E)_{)}=0.058(0.012)}\right)$ and teacher-reports $\left(\hat{\beta}_{\mathrm{ADHD} \_\mathrm{Y}}(\mathrm{SE})=0.077(0.011)\right.$ to $\left.\hat{\beta}_{\mathrm{ADHD} \_12 \mathrm{Y}}=0.088(0.012)\right)$, but not parentreported low prosociality between the ages of 4 and 10 years $\left(\hat{\beta}_{\mathrm{ADHD} \_4 \mathrm{Y}}(\mathrm{SE})=-0.0049(0.0077)\right.$ to $\left.\hat{\beta}_{\text {ADHD_10Y }}(\mathrm{SE})=0.0094(0.0063)\right)$. Polygenic association with MD-PRS increased with age and was larger for peer problems $\left(\hat{\beta}_{\mathrm{MD} \_4 \mathrm{Y}}(\mathrm{SE})=0.044(0.0097)\right.$ to $\left.\hat{\beta}_{\mathrm{MD} \_17 \mathrm{Y}}(\mathrm{SE})=0.090(0.012)\right)$ than low prosociality $\left(\hat{\beta}_{\mathrm{MD} \_4 \mathrm{Y}}(\mathrm{SE})=-0.0033(0.0078)\right.$ to $\left.\hat{\beta}_{\mathrm{MD} \_17 \mathrm{Y}}(\mathrm{SE})=0.042(0.0095)\right)$ with evidence for an association with low prosociality only from the age of 9 years onwards $\left(\hat{\beta}_{\mathrm{MD} \_ \text {_Y }}(\mathrm{SE})=0.014(0.0061)\right)$. In contrast, association effects of schizophrenia-PRS risk with social behaviour were only found for low prosociality $\left(\hat{\beta}_{\mathrm{SCZ} \_4}(\mathrm{SE})=0.024(0.0079)\right.$ to $\left.\hat{\beta}_{\mathrm{SCZ} \_17 \mathrm{Y}}(\mathrm{SE})=0.047(0.0096)\right)$, but not peer problems $\left(\hat{\beta}_{\mathrm{SCZ} \_4}(\mathrm{SE})=-0.0036(0.0098)\right.$ to $\left.\hat{\beta}_{\text {SCZ_17Y }}(\mathrm{SE})=0.019(0.0120)\right)$. ASD-PRS association effects were stable across age, but larger for peer problems $\left(\hat{\beta}_{\mathrm{ASD}}(\mathrm{SE})=0.058(0.0070)\right)$ than low prosociality $\left(\hat{\beta}_{\mathrm{ASD}}(\mathrm{SE})=0.021(0.0063)\right)$.

Together, these findings are consistent with distinct association profiles for social behaviour across psychiatric conditions.

Table 2, Figure 3here

\section{Discussion}


medRxiv preprint doi: https://doi.org/10.1101/2021.06.28.21259532; this version posted July 1, 2021. The copyright holder for this preprint (which was not certified by peer review) is the author/funder, who has granted medRxiv a license to display the preprint in perpetuity. It is made available under a CC-BY-NC-ND 4.0 International license .

Investigating polygenic links between risk for psychiatric disorder and populationbased social behaviour, this study identified marked differences in genetic associations between psychiatric disorders and a spectrum of social-behavioural difficulties. We observed robust evidence for shared genetic influences between child and adolescent social difficulties and polygenic risk for ADHD, MD and schizophrenia across two large UK population-based cohorts in a univariate association approach. Combining univariate findings in a meta-regression approach, we identified further evidence for association between ASD risk and social difficulties. Here, we showed that the identified meta-analytic association profiles systematically varied with age-, reporter- and trait-specific social symptoms across disorders. These findings suggest a diverse genetic landscape of social phenotypes that is differentially shared with psychiatric disorder. As such, our results refine previous research demonstrating genetic overlap with psychiatric risk for social behaviourrelated traits such as emotion recognition in childhood and adolescence ${ }^{31,32}$, self-reported empathy $^{33}$, loneliness ${ }^{34}$, and sociability ${ }^{35}$ in adults.

We observed age-specific effects for ADHD, MD and schizophrenia risk indicating polygenic links with social behaviour that increased from childhood to adolescence, detectable at 4 years of age onwards. These findings confirm previously reported developmental changes in the genetic overlap of schizophrenia risk with social communication $^{36}$. While a developmental increase in genetic association effects is in line with the typical onset of MD and schizophrenia during adolescence and adult life ${ }^{37,38}$, our findings may link to subthreshold social difficulties preceding clinical diagnosis ${ }^{39,40}$ or earlyonset cases, which are thought to convey more severe symptoms ${ }^{41,42}$. The age-specific increase in association between risk for ADHD, a typical childhood-onset disorder, and scores for both low prosociality and peer problems during the course of development suggests that the genetic link with social behaviour may progress into adulthood ${ }^{43}$.

For ADHD risk only, we identified reporter-specific genetic effects, with stronger genetic links for teacher-reported compared to parent-reported social behaviour. Social behaviour at school as reported by teachers evaluates rule-oriented behaviour ${ }^{44}$, but also adequate peer-peer interactions among children of the same age. Therefore, school environments may, specifically, expose behavioural difficulties of children with ADHD. Problems may arise due to children's high levels of distractibility but also their disruptive/oppositional behaviours, consistent with teacher-reported, but not parent-reported oppositional defiant disorder symptoms predicting less prosocial behaviour ${ }^{1}$.

Across disorders, we found evidence for social trait-specific effects shaping polygenic links with ADHD, ASD, MD and schizophrenia risk. The sole association of schizophrenia 
risk with low prosociality, but not peer problems, may reflect specific impairments in social cognition and a lack of social interest and empathy in psychotic disorders ${ }^{5}$. In contrast, the stronger genetic association of ADHD, ASD, and MD risk with peer problems, compared to prosocial scores, may reflect genetic links with socially disruptive behaviours and poor social skills, potentially related to difficulties with communication, emotion regulation, executive functioning, and/or social isolation ${ }^{4,45,46}$. The similarity in polygenic trait effects for ADHD, $A S D$, and $M D$ is in line with previously reported similarities in social symptoms at the phenotypic level ${ }^{47-49}$ and genetic correlations between these conditions ${ }^{50}$.

The absence of genetic interrelationships with BP is consistent with previous reports $^{33,35,51}$ and either reflects lack of power or suggests that, genetically, social symptoms may not be directly involved in the genetic aetiology of the disorder.

Given the robustness of univariate polygenic signals across two populationbased/community-based cohorts, our findings suggest that the identified association profiles capture differences in genetic covariance between social traits and disorders, reflecting differences in underlying aetiological mechanisms: (1) The discordant social trait-specific association pattern for schizophrenia compared to ADHD, ASD, and MD risk suggests that the aetiological spectrum of social difficulties is distinct across disorders, supporting targeted treatment strategies for psychotic versus non-psychotic disorders ${ }^{52}$. (2) Teacher-specific effects shaping polygenic links with ADHD risk may reflect a subtype of social-behavioural problems within school environments that is influenced by genetic factors unique to ADHD, highlighting the importance of school-related interventions. A lack of power to detect reporter-specific effects for other disorders is a less likely explanation, despite known bias affecting parent-reported measures ${ }^{53}$, given association of parent-reported measures with other psychiatric PRS (Supplementary Figures 1-2). (3) Age-specific changes in genetic associations involving $A D H D, M D$, and schizophrenia risk, but not ASD risk, are likely to reflect the change in overlap between the largely stable symptom spectrum in disorder and developmentally highly variable social problems in the general population. These findings suggest that social-behavioural symptoms during later adolescence most strongly contribute to $A D H D, M D$, and schizophrenia genetic architectures underscoring the need for early-life interventions. Conversely, the lack of age-specific changes in the association of ASD risk with social behaviour suggests that these polygenic links involve social problems that already emerge before or at the age of 4 years and remain developmentally stable, consistent with the early social core deficits in $\mathrm{ASD}^{2}$. These findings contrast with the developmental decline in the genetic overlap of ASD risk with social communication that was previously reported $^{36}$, possibly reflecting differences in social-behavioural versus - 
communication-related skills, where the latter rely more strongly on social cognition, and verbal and non-verbal communication ${ }^{7}$.

Our study has several strengths and limitations: We investigated two social traits as reported by parents and teachers across 13 years of child and adolescent development, studying polygenic links with multiple psychiatric conditions, using a count data approach. We robustly identified evidence for genetic association in two large UK populationbased/community-based cohorts, and systematically modelled heterogeneity in polygenic estimates using a random-effects meta-regression approach. However, consistent with other PRS analyses ${ }^{36}$, effect sizes were small, and due to different sets of risk-increasing alleles analysed, a direct comparison of PRS effect size across disorders is not meaningful here. We exclusively investigated social symptoms with the SDQ. Different instruments, including those assessing reciprocal social interactions, might capture additional symptoms and broaden the interpretation of social difficulties in psychiatric disorders, in particular for ASD risk. Furthermore, polygenic signals might be biased by population-based phenomena, such as dynastic effects and non-random mating ${ }^{54}$, but also non-random missingness linked to socio-economic status ${ }^{55,56}$. However, this is less likely as bias would similarly affect uniformly ascertained SDQ scores, resulting in homogeneous and not heterogeneous genetic association profiles. Finally, misclassification of psychiatric disorder and phenotypic heterogeneity may increase genetic correlations across a spectrum of social symptoms ${ }^{57}$. Thus, further studies should refine our findings by replicating across broadly defined social phenotypes in European and non-European cohorts to promote the translation into precision medicine ${ }^{52}$.

In conclusion, our findings reveal marked differences in the social genetic architecture underlying different psychiatric disorders and demonstrate that social symptoms represent a heterogeneous spectrum of related endophenotypes.

\section{Acknowledgements}

We are extremely grateful to all the families who took part in this study, the midwives for their help in recruiting them, and the whole ALSPAC team, which includes interviewers, computer and laboratory technicians, clerical workers, research scientists, volunteers, managers, receptionists and nurses. The UK Medical Research Council and Wellcome (Grant ref: 217065/Z/19/Z) and the University of Bristol provide core support for ALSPAC. This publication is the work of the authors and FS and BSTP will serve as guarantors for the contents of this paper. A comprehensive list of grants funding is available on the ALSPAC website (http://www.bristol.ac.uk/alspac/external/documents/grant-acknowledgements.pdf). 
medRxiv preprint doi: https://doi.org/10.1101/2021.06.28.21259532; this version posted July 1, 2021. The copyright holder for this preprint (which was not certified by peer review) is the author/funder, who has granted medRxiv a license to display the preprint in perpetuity. It is made available under a CC-BY-NC-ND 4.0 International license .

GWAS data was generated by Sample Logistics and Genotyping Facilities at Wellcome Sanger Institute and LabCorp (Laboratory Corporation of America) using support from 23andMe. FS, EV, MvD, BSTP and SEF are supported by the Max Planck Society. BSTP is supported by the Simons Foundation (Award ID: 514787). The authors gratefully acknowledge the ongoing contribution of the participants in the TEDS and their families. TEDS is supported by a programme grant to RP from the UK Medical Research Council (MR/M021475/1 and previously G0901245), with additional support from the US National Institutes of Health (AG046938). RP is supported by a Medical Research Council Professorship award (G19/2). The research leading to these results has also received funding from the European Research Council under the European Union's Seventh Framework Programme (FP7/2007-2013)/ grant agreement $n^{\circ} 602768$. This project has received funding from the European Union's Horizon 2020 research and innovation programme, Marie Sklodowska Curie Actions (MSCA-ITN-2016) Innovative Training Networks (CAPICE grant 721567). KR is supported by a Sir Henry Wellcome Postdoctoral Fellowship.

\section{Conflict of Interest}

The authors declare no conflict of interest.

\section{References}

1. Milledge SV, Cortese S, Thompson M, McEwan F, Rolt M, Meyer B, et al. Peer relationships and prosocial behaviour differences across disruptive behaviours. Eur Child Adolesc Psychiatry 2019; 28: 781-93.

2. American Psychiatric Association. Diagnostic and statistical manual of mental disorders (DSM-5®). American Psychiatric Pub: 2013.

3. Tiğli Filizer A, Cerit C, Tüzün B, Aker AT. Social Aspect of Functioning Deteriorates More Than Individual Aspect in Patients with Remitted Bipolar Disorder. Nöro Psikiyatri Arş 2016; 53: 158-62.

4. Kupferberg A, Bicks L, Hasler G. Social functioning in major depressive disorder. Neurosci Biobehav Rev 2016; 69: 313-32.

5. Green MF, Horan WP, Lee J. Social cognition in schizophrenia. Nat Rev Neurosci 2015; 16: 620-31.

6. Hay DF. Prosocial Development. J Child Psychol Psychiatry 1994; 35: 29-71.

7. Fabiano GA, Vujnovic RK, Pariseau ME. Peer Problems. In Thomas JC, Hersen M (eds.). Handbook of Clinical Psychology Competencies Springer New York: New York, NY, 2010, pp 1563-88. 
medRxiv preprint doi: https://doi.org/10.1101/2021.06.28.21259532; this version posted July 1, 2021. The copyright holder for this preprint (which was not certified by peer review) is the author/funder, who has granted medRxiv a license to display the preprint in perpetuity. It is made available under a CC-BY-NC-ND 4.0 International license .

8. Decety J. The neurodevelopment of empathy in humans. Dev Neurosci 2010; 32: 25767.

9. Saudino KJ, Ronald A, Plomin R. The etiology of behavior problems in 7-year-old twins: substantial genetic influence and negligible shared environmental influence for parent ratings and ratings by same and different teachers. J Abnorm Child Psychol 2005; 33: 113-30.

10. Scourfield J, John B, Martin N, McGuffin P. The development of prosocial behaviour in children and adolescents: a twin study. J Child Psychol Psychiatry 2004; 45: 927-35.

11. Knafo A, Plomin R. Prosocial Behavior From Early to Middle Childhood: Genetic and Environmental Influences on Stability and Change. Dev Psychol 2006; 42: 771-86.

12. St Pourcain B, Haworth CMA, Davis OSP, Wang K, Timpson NJ, Evans DM, et al. Heritability and genome-wide analyses of problematic peer relationships during childhood and adolescence. Hum Genet 2015; 134: 539-51.

13. Demontis D, Walters RK, Martin J, Mattheisen M, Als TD, Agerbo E, et al. Discovery of the first genome-wide significant risk loci for attention deficit/hyperactivity disorder. Nat Genet 2019; 51: 63-75.

14. Grove J, Ripke S, Als TD, Mattheisen M, Walters RK, Won H, et al. Identification of common genetic risk variants for autism spectrum disorder. Nat Genet 2019; 51: 43144.

15. Stahl EA, Breen G, Forstner AJ, McQuillin A, Ripke S, Trubetskoy V, et al. Genomewide association study identifies 30 loci associated with bipolar disorder. Nat Genet 2019; 51: 793-803.

16. Wray NR, Ripke S, Mattheisen M, Trzaskowski M, Byrne EM, Abdellaoui A, et al. Genome-wide association analyses identify 44 risk variants and refine the genetic architecture of major depression. Nat Genet 2018; 50: 668-81.

17. Schizophrenia Working Group of the Psychiatric Genomics Consortium. Biological insights from 108 schizophrenia-associated genetic loci. Nature 2014; 511: 421-7.

18. Martin J, Taylor MJ, Lichtenstein P. Assessing the evidence for shared genetic risks across psychiatric disorders and traits. Psychol Med 2018; 48: 1759-74.

19. Schlag F, St Pourcain B, Rimfeld K, Allegrini A, Plomin R, Buitelaar J, et al. Investigation of association profiles between polygenic risk for psychiatric disorder and social skill sets in the general population. 2020.osf.io/p5wah

20. Boyd A, Golding J, Macleod J, Lawlor DA, Fraser A, Henderson J, et al. Cohort Profile: the 'children of the 90s'--the index offspring of the Avon Longitudinal Study of Parents and Children. Int J Epidemiol 2013; 42: 111-27.

21. Rimfeld K, Malanchini M, Spargo T, Spickernell G, Selzam S, McMillan A, et al. Twins Early Development Study: A Genetically Sensitive Investigation into Behavioral and Cognitive Development from Infancy to Emerging Adulthood. Twin Res Hum Genet 2019; 22: 508-13. 
medRxiv preprint doi: https://doi.org/10.1101/2021.06.28.21259532; this version posted July 1, 2021. The copyright holder for this preprint (which was not certified by peer review) is the author/funder, who has granted medRxiv a license to display the preprint in perpetuity. It is made available under a CC-BY-NC-ND 4.0 International license .

22. Fraser A, Macdonald-Wallis C, Tilling K, Boyd A, Golding J, Davey Smith G, et al. Cohort Profile: the Avon Longitudinal Study of Parents and Children: ALSPAC mothers cohort. Int J Epidemiol 2013; 42: 97-110.

23. Goodman R. The Strengths and Difficulties Questionnaire: a research note. J Child Psychol Psychiatry 1997; 38: 581-6.

24. Wray NR, Lee SH, Mehta D, Vinkhuyzen AAE, Dudbridge F, Middeldorp CM. Research review: polygenic methods and their application to psychiatric traits. $J$ Child Psychol Psychiatry 2014; 55: 1068-87.

25. Bates $\mathrm{D}$, Mächler M, Bolker B, Walker S. Fitting linear mixed-effects models using Ime4. ArXiv Prepr ArXiv14065823 2014;

26. McFadden D. Conditional logit analysis of qualitative choice behavior. 1973;

27. Nyholt DR. A Simple Correction for Multiple Testing for Single-Nucleotide Polymorphisms in Linkage Disequilibrium with Each Other. Am J Hum Genet 2004; 74: 765-9.

28. Dudbridge F. Power and Predictive Accuracy of Polygenic Risk Scores. PLOS Genet 2013; 9: e1003348.

29. Viechtbauer W. Conducting meta-analyses in $\mathrm{R}$ with the metafor package. J Stat Softw 2010; 36: 1-48.

30. Lajeunesse MJ. Meta-analysis and the comparative phylogenetic method. Am Nat 2009; 174: 369-81.

31. Germine L, Robinson EB, Smoller JW, Calkins ME, Moore TM, Hakonarson H, et al. Association between polygenic risk for schizophrenia, neurocognition and social cognition across development. Transl Psychiatry 2016; 6: e924-e924.

32. Wendt FR, Carvalho CM, Gelernter J, Polimanti R. The effect of the genetic liability to autism spectrum disorder on emotion recognition in young unaffected probands from a population-based cohort. medRxiv 2019; 19001230.

33. Warrier V, Toro R, Chakrabarti B, Børglum AD, Grove J, Hinds DA, et al. Genome-wide analyses of self-reported empathy: correlations with autism, schizophrenia, and anorexia nervosa. Transl Psychiatry 2018; 8: 1-10.

34. Abdellaoui A, Nivard MG, Hottenga J-J, Fedko I, Verweij KJH, Baselmans BML, et al. Predicting loneliness with polygenic scores of social, psychological and psychiatric traits. Genes Brain Behav 2018; 17: e12472.

35. Bralten J, Klemann C, Mota NR, Witte WD, Arango C, Fabbri C, et al. Genetic underpinnings of sociability in the UK Biobank. bioRxiv 2019; 781195.

36. St Pourcain B, Robinson EB, Anttila V, Sullivan BB, Maller J, Golding J, et al. ASD and schizophrenia show distinct developmental profiles in common genetic overlap with population-based social communication difficulties. Mol Psychiatry 2018; 23: 263-70.

37. Kessler RC, Angermeyer M, Anthony JC, de Graaf R, Demyttenaere K, Gasquet I, et al. Lifetime prevalence and age-of-onset distributions of mental disorders in the World 
medRxiv preprint doi: https://doi.org/10.1101/2021.06.28.21259532; this version posted July 1, 2021. The copyright holder for this preprint (which was not certified by peer review) is the author/funder, who has granted medRxiv a license to display the preprint in perpetuity. It is made available under a CC-BY-NC-ND 4.0 International license .

Health Organization's World Mental Health Survey Initiative. World Psychiatry 2007; 6: 168-76.

38. Werf M van der, Hanssen M, Köhler S, Verkaaik M, Verhey FR, Investigators R, et al. Systematic review and collaborative recalculation of 133693 incident cases of schizophrenia. Psychol Med 2014; 44: 9-16.

39. Katz SJ, Conway CC, Hammen CL, Brennan PA, Najman JM. Childhood Social Withdrawal, Interpersonal Impairment, and Young Adult Depression: A Mediational Model. J Abnorm Child Psychol 2011; 39: 1227-38.

40. Bucci P, Mucci A, Piegari G, Nobile M, Pini S, Rossi A, et al. Characterization of premorbid functioning during childhood in patients with deficit vs. non-deficit schizophrenia and in their healthy siblings. Schizophr Res 2016; 174: 172-6.

41. Yalin N, Young AH. The Age of Onset of Unipolar Depression. In de Girolamo G, McGorry PD, Sartorius N (eds.). Age of Onset of Mental Disorders: Etiopathogenetic and Treatment Implications Springer International Publishing: Cham, 2019, pp 111-24.

42. Immonen J, Jääskeläinen E, Korpela H, Miettunen J. Age at onset and the outcomes of schizophrenia: A systematic review and meta-analysis. Early Interv Psychiatry 2017; 11: 453-60.

43. Friedman SR, Rapport LJ, Lumley M, Tzelepis A, VanVoorhis A, Stettner L, et al. Aspects of social and emotional competence in adult attention-deficit/hyperactivity disorder. Neuropsychology 2003; 17: 50-8.

44. Adams GR, Ryan BA, Ketsetzis M, Keating L. Rule compliance and peer sociability: A study of family process, school-focused parent-child interactions, and children's classroom behavior. J Fam Psychol 2000; 14: 237-50.

45. Hoza B. Peer Functioning in Children With ADHD. J Pediatr Psychol 2007; 32: 655-63.

46. Matthias C, LaVelle JM, Johnson DR, Wu Y-C, Thurlow ML. Exploring predictors of bullying and victimization of students with autism spectrum disorder (ASD): findings from NLTS 2012. J Autism Dev Disord 2021; 1-12.

47. Feldman JS, Tung I, Lee SS. Social Skills Mediate the Association of ADHD and Depression in Preadolescents. J Psychopathol Behav Assess 2017; 39: 79-91.

48. Powell V, Riglin L, Hammerton G, Eyre O, Martin J, Anney R, et al. What explains the link between childhood ADHD and adolescent depression? Investigating the role of peer relationships and academic attainment. Eur Child Adolesc Psychiatry 2020; 29: 1581-91.

49. Oakley BF, Tillmann J, Ahmad J, Crawley D, San José Cáceres A, Holt R, et al. How do core autism traits and associated symptoms relate to quality of life? Findings from the Longitudinal European Autism Project. Autism 2021; 25: 389-404.

50. Cross-Disorder Group of the Psychiatric Genomics Consortium. Genomic relationships, novel loci, and pleiotropic mechanisms across eight psychiatric disorders. Cell 2019; 179: 1469-82.

51. Akingbuwa WA, Hammerschlag AR, Jami ES, Allegrini AG, Karhunen V, Sallis H, et al. Genetic Associations Between Childhood Psychopathology and Adult Depression and 
medRxiv preprint doi: https://doi.org/10.1101/2021.06.28.21259532; this version posted July 1, 2021. The copyright holder for this preprint (which was not certified by peer review) is the author/funder, who has granted medRxiv a license to display the preprint in perpetuity.

It is made available under a CC-BY-NC-ND 4.0 International license .

Associated Traits in 42998 Individuals: A Meta-Analysis. JAMA Psychiatry 2020; 77: 715-28.

52. Rees E, Owen MJ. Translating insights from neuropsychiatric genetics and genomics for precision psychiatry. Genome Med 2020; 12: 1-16.

53. Scourfield J, John B, Martin N, McGuffin P. The development of prosocial behaviour in children and adolescents: a twin study. J Child Psychol Psychiatry 2004; 45: 927-35.

54. Maes HHM, Neale MC, Kendler KS, Hewitt JK, Silberg JL, Foley DL, et al. Assortative mating for major psychiatric diagnoses in two population-based samples. Psychol Med 1998; 28: 1389-401.

55. Morris TT, Davies NM, Hemani G, Smith GD. Population phenomena inflate genetic associations of complex social traits. Sci Adv 2020; 6: eaay0328.

56. Taylor AE, Jones HJ, Sallis H, Euesden J, Stergiakouli E, Davies NM, et al. Exploring the association of genetic factors with participation in the Avon Longitudinal Study of Parents and Children. Int J Epidemiol 2018; 47: 1207-16.

57. van Rheenen W, Peyrot WJ, Schork AJ, Lee SH, Wray NR. Genetic correlations of polygenic disease traits: from theory to practice. Nat Rev Genet 2019; 20: 567-81. 
medRxiv preprint doi: https://doi.org/10.1101/2021.06.28.21259532; this version posted July 1, 2021. The copyright holder for this preprint (which was not certified by peer review) is the author/funder, who has granted medRxiv a license to display the preprint in perpetuity.

\section{Figure legends}

Figure 1: Polygenic scoring analyses between social behaviour and psychiatric disorder in ALSPAC.

$\triangle$ McFadden's- $R^{2}$ is shown for the prediction of low-prosociality and peer-problem scores by ADHD-PRS (a, b), ASD-PRS (c, d), BP-PRS (e,f), MD-PRS (g, h), SCZ-PRS (i, j).

Psychiatric disorder samples (ADHD-PGC/iPSYCH, ASD-PGC/iPSYCH, BP-PGC, MD$P G C / U K B B$, and SCZ-PGC) were used to construct Z-standardised PRS in ALSPAC (ADHD-PRS, ASD-PRS, BP-PRS, MD-PRS, and SCZ-PRS) at multiple $P$-value thresholds. Association analyses with social behaviour (low prosociality and peer problems) were conducted using negative binomial regression (multiple-testing corrected $P$-value: ${ }^{*} P \leq 0.001$ ).

ADHD - Attention-deficit/hyperactivity disorder; ALSPAC - Avon Longitudinal study of Parents and Children; ASD - Autism spectrum disorders; BP - Bipolar disorder; iPSYCH Lundbeck Foundation Initiative for Integrative Psychiatric Research; MD- Major depression; PGC - Psychiatric Genomics consortium; PRS-Polygenic risk scores; $P_{\mathrm{T}}$ - PRS threshold; SCZ - Schizophrenia

Low-prosociality and peer-problem scores were assessed using the Strengths-andDifficulties questionnaire. 
medRxiv preprint doi: https://doi.org/10.1101/2021.06.28.21259532; this version posted July 1, 2021. The copyright holder for this preprint (which was not certified by peer review) is the author/funder, who has granted medRxiv a license to display the preprint in perpetuity.

It is made available under a CC-BY-NC-ND 4.0 International license.

Figure 2: Polygenic scoring analyses between social behaviour and psychiatric disorder in TEDS.

$\triangle$ McFadden's- $R^{2}$ is shown for the prediction of low-prosociality and peer-problem scores by $\operatorname{ADHD-PRS}(a, b), \operatorname{ASD}-P R S(c, d)$, BP-PRS (e,f), MD-PRS (g, h), SCZ-PRS (i, j).

Psychiatric disorder samples (ADHD-PGC/iPSYCH, ASD-PGC/iPSYCH, BP-PGC, MD$P G C / U K B B$, and SCZ-PGC) were used to construct Z-standardised PRS in TEDS (ADHDPRS, ASD-PRS, BP-PRS, MD-PRS, and SCZ-PRS) at multiple $P$-value thresholds. Association analyses with social behaviour (low prosociality and peer problems) were conducted using negative binomial regression (multiple-testing corrected one-sided $P$-value: $\left.{ }^{*} P \leq 0.0017\right)$.

ADHD - Attention-deficit/hyperactivity disorder; ASD - Autism spectrum disorders; BP Bipolar disorder; iPSYCH - Lundbeck Foundation Initiative for Integrative Psychiatric Research; MD- Major depression; PGC - Psychiatric Genomics consortium; PRS-Polygenic risk scores; $P_{\mathrm{T}}$ - PRS threshold; SCZ - Schizophrenia; TEDS - Twins Early Development Study

Low-prosociality and peer-problem scores were assessed using the Strengths-andDifficulties questionnaire. 
medRxiv preprint doi: https://doi.org/10.1101/2021.06.28.21259532; this version posted July 1, 2021. The copyright holder for this preprint (which was not certified by peer review) is the author/funder, who has granted medRxiv a license to display the preprint in perpetuity.

It is made available under a CC-BY-NC-ND 4.0 International license.

Figure 3: Meta-analytically predicted PRS effects for psychiatric disorder with social behaviour.

For each disorder (ADHD, ASD, BP, MD and schizophrenia) 29 SDQ-based PRS effects from ALSPAC and TEDS (at $P_{\mathrm{T}} \leq 0.1$ ) were combined using random-effects meta-regression and predicted by age-, reporter- (parent versus teacher), and trait- (low prosociality versus peer problems) specific social symptoms. Predicted estimates for PRS effects (used to fit the meta-regression model) are shown as dots.

ADHD - Attention-Deficit/Hyperactivity Disorder; ALSPAC - Avon Longitudinal study of Parents and Children; ASD - Autism spectrum disorders; BP - Bipolar disorder; MD- Major depression; PRS-Polygenic risk scores; $P_{\mathrm{T}}$ - PRS threshold; SCZ - Schizophrenia; SDQ Strengths-and-Difficulties questionnaire; TEDS - Twins Early Development Study; Y - years 


\section{Tables}

Table 1: Descriptive information of low prosociality and peer problems in ALSPAC and TEDS.

\begin{tabular}{|c|c|c|c|c|c|}
\hline & \multirow{2}{*}{$\begin{array}{c}\text { Age (years) } \\
\text { Mean (SD) }\end{array}$} & \multirow{2}{*}{$\begin{array}{c}\text { Variable score } \\
\text { Mean (SD) } \\
\end{array}$} & \multirow[b]{2}{*}{$\%$ Males } & \multirow[b]{2}{*}{$\mathbf{N}$} \\
\hline & & & & & \\
\hline \multicolumn{6}{|l|}{ ALSPAC } \\
\hline \multicolumn{6}{|l|}{ Low prosociality ${ }^{1}$} \\
\hline \multirow[t]{5}{*}{ Parent-reported: } & $7 Y$ & $6.79(0.11)$ & $1.82(1.75)$ & 51 & 5610 \\
\hline & $10 Y$ & $9.65(0.12)$ & $1.66(1.65)$ & 50 & 5670 \\
\hline & $12 Y$ & $11.72(0.13)$ & $1.65(1.68)$ & 50 & 5268 \\
\hline & $13 Y$ & $13.16(0.18)$ & $2.76(1.73)$ & 50 & 5069 \\
\hline & $17 Y$ & $16.84(0.36)$ & $1.97(1.87)$ & 48 & 4151 \\
\hline \multirow[t]{2}{*}{ Teacher-reported: } & $8 Y$ & $8.33(0.31)$ & $2.21(2.42)$ & 50 & 3686 \\
\hline & $11 Y$ & $11.16(0.33)$ & $2.06(2.35)$ & 50 & 4417 \\
\hline \multicolumn{6}{|l|}{ Peer problems } \\
\hline \multirow[t]{5}{*}{ Parent-reported: } & $7 Y$ & $6.79(0.11)$ & $1.02(1.04)$ & 51 & 5608 \\
\hline & $10 Y$ & $9.65(0.12)$ & $1.1(1.49)$ & 50 & 5661 \\
\hline & $12 Y$ & $11.72(0.13)$ & $1.1(1.56)$ & 50 & 5263 \\
\hline & $13 Y$ & $13.16(0.18)$ & $1.19(1.61)$ & 50 & 5061 \\
\hline & $17 Y$ & $16.84(0.36)$ & $1.11(1.51)$ & 48 & 4156 \\
\hline \multirow[t]{2}{*}{ Teacher-reported: } & $8 Y$ & $8.33(0.31)$ & $1.13(1.74)$ & 50 & 3689 \\
\hline & $11 Y$ & $11.16(0.33)$ & $1.2(1.85)$ & 50 & 4417 \\
\hline \multicolumn{6}{|l|}{ TEDS } \\
\hline \multicolumn{6}{|l|}{ Low prosociality $^{1}$} \\
\hline \multirow[t]{5}{*}{ Parent-reported: } & $4 Y$ & $4.04(0.12)$ & $2.6(1.86)$ & 48 & 6958 \\
\hline & $7 Y$ & $7.06(0.25)$ & $1.84(1.79)$ & 48 & 7112 \\
\hline & $9 Y$ & $9.01(0.29)$ & $2.71(1.71)$ & 47 & 3375 \\
\hline & $11 Y$ & $11.25(0.7)$ & $1.46(1.65)$ & 48 & 6039 \\
\hline & $16 Y$ & $16.31(0.68)$ & $1.74(1.94)$ & 45 & 5252 \\
\hline \multirow[t]{3}{*}{ Teacher-reported: } & $7 Y$ & $7.2(0.28)$ & $2.68(2.36)$ & 49 & 5900 \\
\hline & $9 Y$ & $9.03(0.29)$ & $2.44(2.26)$ & 47 & 2825 \\
\hline & $12 Y$ & $11.5(0.66)$ & $1.99(2.09)$ & 47 & 4931 \\
\hline \multicolumn{6}{|l|}{ Peer problems } \\
\hline \multirow[t]{4}{*}{ Parent-reported: } & $4 Y$ & $4.04(0.12)$ & $1.52(1.54)$ & 48 & 6948 \\
\hline & $7 Y$ & $7.06(0.25)$ & $1.01(1.45)$ & 48 & 7112 \\
\hline & $9 Y$ & $9.01(0.29)$ & $1.11(1.59)$ & 47 & 3370 \\
\hline & $11 Y$ & $11.25(0.7)$ & $1.11(1.54)$ & 48 & 6023 \\
\hline \multirow[t]{3}{*}{ Teacher-reported: } & $7 Y$ & $7.2(0.28)$ & $1.07(1.48)$ & 49 & 5900 \\
\hline & $9 Y$ & $9.03(0.29)$ & $0.85(1.47)$ & 47 & 2828 \\
\hline & $12 Y$ & $11.51(0.66)$ & $1.04(1.6)$ & 47 & 4964 \\
\hline
\end{tabular}

${ }^{1}$ Reverse coded SDQ prosocial scale.

ALSPAC - Avon Longitudinal study of Parents and Children; SDQ - Strengths-and-Difficulties questionnaire; TEDS - Twins Early Development Study; Y - Age in years

All low-prosociality and peer-problem scores were assessed using the Strengths-andDifficulties questionnaire. 
medRxiv preprint doi: https://doi.org/10.1101/2021.06.28.21259532; this version posted July 1, 2021. The copyright holder for this preprint (which was not certified by peer review) is the author/funder, who has granted medRxiv a license to display the preprint in perpetuity. It is made available under a CC-BY-NC-ND 4.0 International license. 
medRxiv preprint doi: https://doi.org/10.1101/2021.06.28.21259532; this version posted July 1, 2021. The copyright holder for this preprint (which was not certified by peer review) is the author/funder, who has granted medRxiv a license to display the preprint in perpetuity.

It is made available under a CC-BY-NC-ND 4.0 International license .

Table 2: Random-effects meta-regression across psychiatric PRS effects on socialbehavioural symptoms ${ }^{1}$.

\begin{tabular}{|c|c|c|c|}
\hline \multicolumn{4}{|l|}{ ADHD-PRS $\left(R^{2}=0.88\right)$} \\
\hline Parameter & $\theta$ (SE) & Z-value & $P$-value \\
\hline $\begin{array}{l}\text { Intercept (Age 4, parent-reported, low } \\
\text { prosociality) }\end{array}$ & $-0.015(0.01)$ & -1.49 & 0.14 \\
\hline Age (Centered at 4 years) & $0.0025(0.00089)$ & 2.86 & 0.0042 \\
\hline Reporter (Teacher-reported) & $0.044(0.0085)$ & 5.16 & $2.5 \times 10^{-7}$ \\
\hline Trait (Peer problems) & $0.03(0.0089)$ & 3.38 & $7.3 \times 10^{-4}$ \\
\hline \multicolumn{4}{|l|}{ ASD-PRS $\left(R^{2}=0.58\right)$} \\
\hline Parameter & $\theta$ (SE) & Z-value & $P$-value \\
\hline Intercept (Low prosociality) & $0.021(0.0063)$ & 3.36 & $7.7 \times 10^{-4}$ \\
\hline Trait & $0.037(0.0083)$ & 4.47 & $7.9 \times 10^{-6}$ \\
\hline \multicolumn{4}{|l|}{ BP-PRS $\left(R^{2}=0.00\right)$} \\
\hline Parameter & $\theta$ (SE) & Z-value & $P$-value \\
\hline Intercept & $0.0054(0.0056)$ & 0.98 & 0.33 \\
\hline \multicolumn{4}{|l|}{ MD-PRS $\left(R^{2}=0.84\right)$} \\
\hline Parameter & $\theta$ (SE) & Z-value & $P$-value \\
\hline Intercept (Age 4, low prosociality) & $-0.018(0.011)$ & -1.66 & 0.096 \\
\hline Age (Centered at 4 years) & $0.0035(0.00095)$ & 3.74 & $1.9 \times 10^{-4}$ \\
\hline Trait (Peer problems) & $0.048(0.0093)$ & 5.14 & $2.8 \times 10^{-7}$ \\
\hline \multicolumn{4}{|l|}{ Schizophrenia-PRS $\left(R^{2}=0.45\right)$} \\
\hline Parameter & $\theta$ (SE) & Z-value & $P$-value \\
\hline Intercept (Low prosociality) & $0.017(0.011)$ & 1.55 & 0.12 \\
\hline Age (Centered at 4 years) & $0.0018(0.00096)$ & 1.86 & 0.063 \\
\hline Trait (Peer problems) & $-0.027(0.0094)$ & -2.94 & 0.0033 \\
\hline
\end{tabular}

1 PRS association effects for ADHD, ASD, BP, MD and schizophrenia risk (based on negative binominal regression) were combined across 29 social symptoms (14 ALSPACbased + 15 TEDS-based; at $P_{\mathrm{T}} \leq 0.1$ ) using random-effects meta-regressions, accounting for phenotypic correlations between social scores. Here, the most parsimonious models are shown with the predictors $(\theta)$ of PRS effect heterogeneity including age-, reporter- (parent versus teacher reports), and trait-specific differences in social behaviour (low prosociality versus peer problems).

ADHD - Attention-Deficit/Hyperactivity Disorder; ALSPAC - Avon Longitudinal study of Parents and Children; ASD - Autism spectrum disorder; BP - Bipolar disorder; MD- Major depression; PRS-Polygenic risk scores; $P_{\mathrm{T}}$ - PRS threshold; TEDS - Twins Early Development Study 
Figure 1
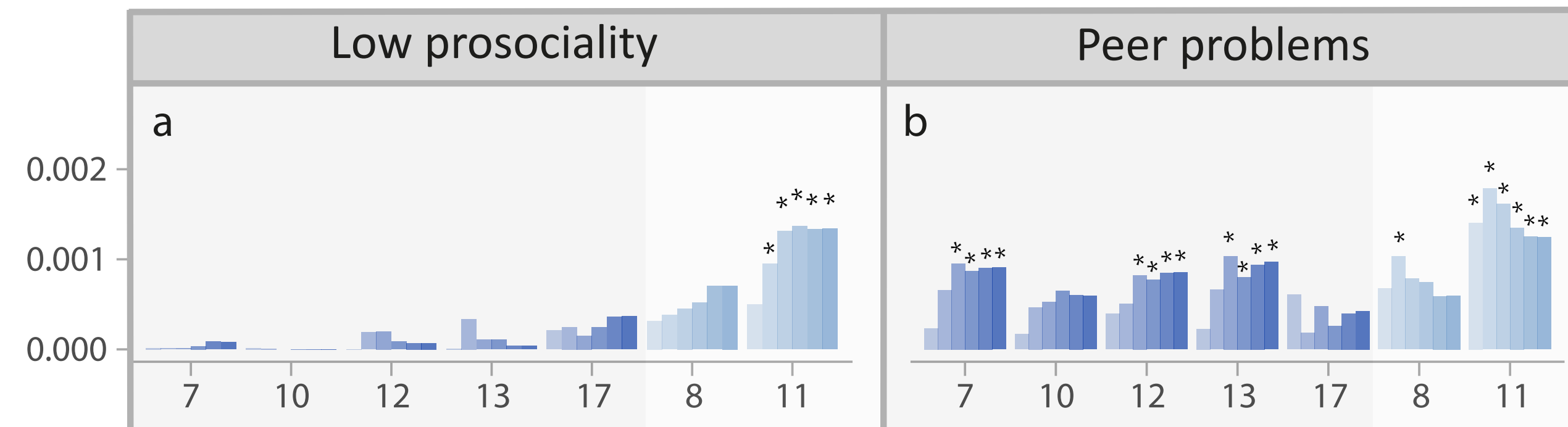

뭄

medRxiv preprint doi: https://doiorg/10.1101/2021.06.28.21259532; this version posted July 1, 2021. The copyright holder for this $p$ eprin

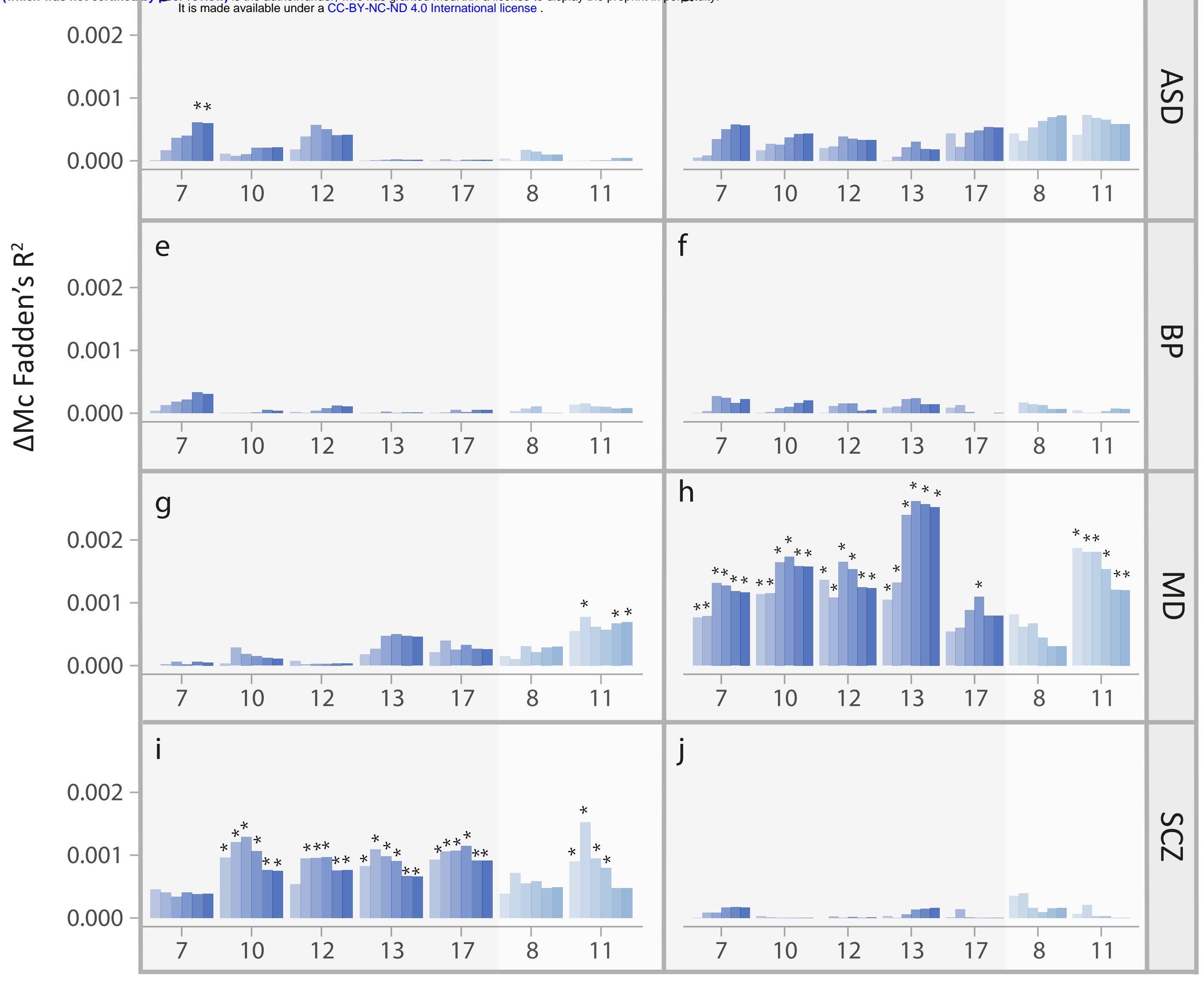

$P$-value threshold:

0.001
0.01
0.05
0.1
0.7
1

Reporter:

Parent

Teacher

Age (years) 


\section{Figure 2}
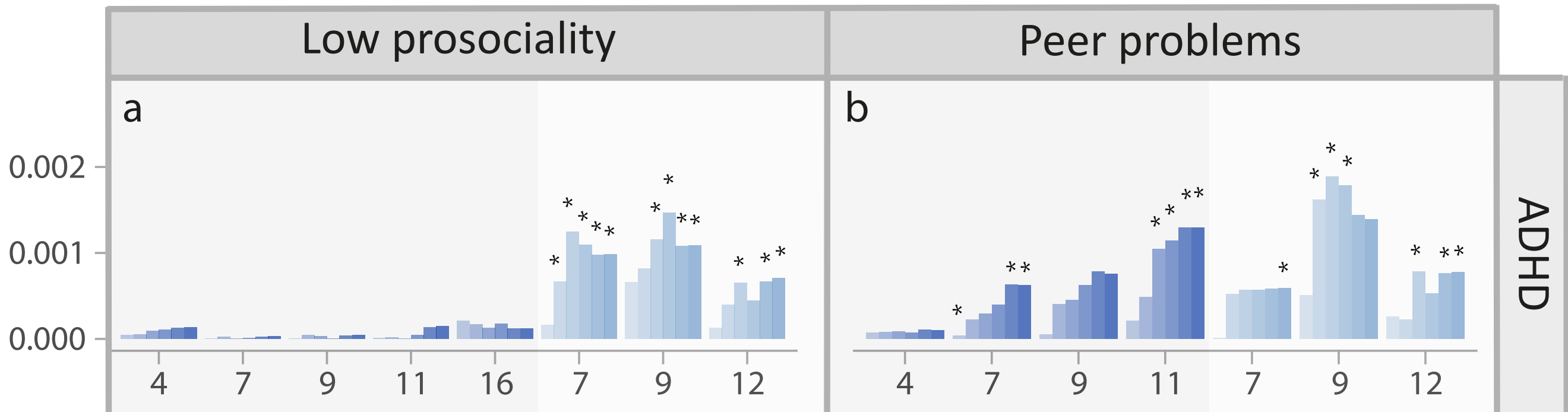

(which was not certified by porg



$P$-value threshold:

0.001
0.01
0.05
0.1
0.7
1

Reporter:

Parent

Teacher

Age (years) 


\section{Figure 3}

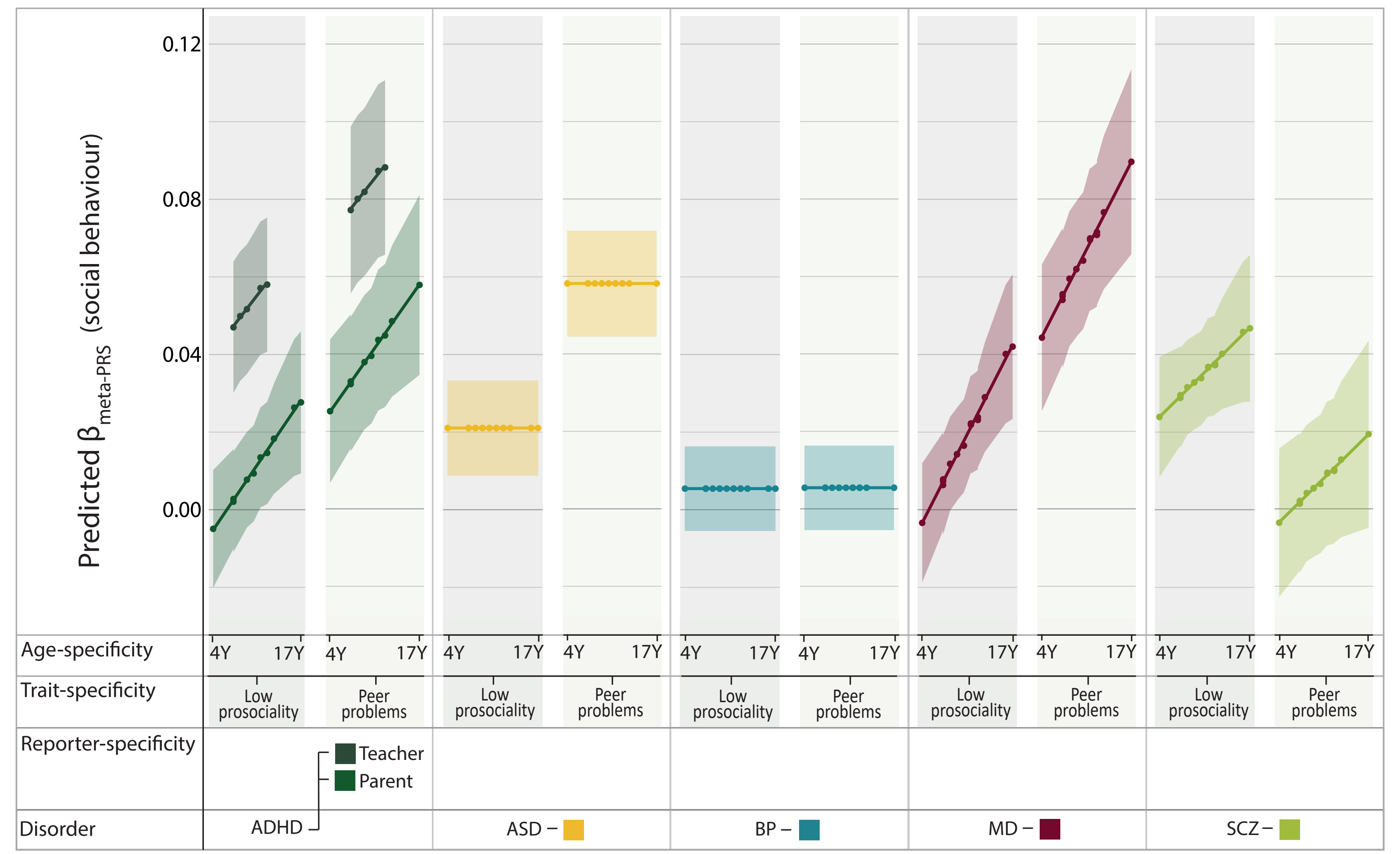

